\title{
Hip pathologies in mucopolysaccharidosis type III
}

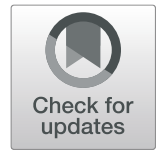

\author{
Sandra Rafaela Breyer ${ }^{1,2,3^{*}}$ (D) Eik Vettorazzi ${ }^{4}$, Leonie Schmitz ${ }^{4}$, Amit Gulati ${ }^{4}$, Katharina Maria von Cossel ${ }^{3,5}$, \\ Alexander Spiro ${ }^{1,2,3}$, Martin Rupprecht ${ }^{1,2,3}$, Ralf Stuecker ${ }^{1,2,3}$ and Nicole Maria Muschol ${ }^{3,5}$
}

\begin{abstract}
Background: Mucopolysaccharidosis type III (MPS III) comprises a group of rare lysosomal storage diseases. Although musculoskeletal symptoms are less pronounced than in other MPS subtypes, pathologies of hip and spine have been reported in MPS III patients. The purpose of this study was to describe hip pathologies and influencing parameters in MPS III patients.
\end{abstract}

Methods: A retrospective chart review was performed for 101 MPS III patients. Thirty-two patients met the inclusion criteria of enzymatically or genetically confirmed diagnosis and anteroposterior radiograph of the hips. Modified Ficat classification, Wiberg's center-edge angle, and Reimer's migration percentage were measured.

Results: The mean age at data assessment was 11.0 years (SD 5.7). Osteonecrosis of the femoral head was observed in 17/32 patients. No statistically significant association was found between these changes and age, sex, or MPS III subtype. Patients with a severe phenotype showed significantly higher rates of osteonecrosis (14/17) than patients with an intermediate phenotype. Hip dysplasia was present in 9/32 patients and was significantly associated with osteonecrosis of the femoral head $(p=0.04)$.

Conclusions: The present study demonstrates a high rate of hip pathologies in MPS III patients. Hip dysplasia and severe phenotype were significantly correlated with osteonecrosis of the femoral head. Therefore, radiographs of the hips are highly recommended in baseline and follow-up assessments of MPS III patients.

Trial registration: Retrospectively registered.

Keywords: Mucopolysaccharidosis type III, Sanfilippo syndrome, MPS, Osteonecrosis, Hip dysplasia, Femoral head, Pain, Skeletal disease, Skeletal dysplasia, Dysostosis multiplex

\section{Background}

Mucopolysaccharidosis type III (MPS III, Sanfilippo syndrome) is the most common type of MPS and comprises a group of clinically indistinguishable lysosomal storage diseases. These rare, autosomal recessive disorders are caused by deficiency of one of four

\footnotetext{
* Correspondence: sandra.r.breyer@gmail.com;

sandra.breyer@kinderkrankenhaus.net

'Department of Pediatric Orthopedics, Children's Hospital Altona, Bleickenallee 38, 22763 Hamburg, Germany

${ }^{2}$ Department of Orthopedics, University Medical Center Hamburg-Eppendorf, 20246 Hamburg, Germany

Full list of author information is available at the end of the article
}

enzymes (subtypes A-D) involved in the degradation of heparan sulfate (HS), including heparan N-sulfatase (sulfamidase), $\alpha$-N-acetylglucosaminidase (NAGLU), acetyl-coenzyme A $\alpha$-glucosaminide- $\mathrm{N}$-acetyltransferase, and $\mathrm{N}$-acetylglucosamine-6-sulfatase [1]. MPS IIIA is the most common subtype in northern Europe, with an estimated incidence in Germany of 1 in 63,700 births [2].

The clinical manifestations and disease progression of the MPS III subtypes vary due to differences in residual enzyme activities caused by several mutations in the four affected genes. Patients with MPS III present with

C C The Author(s). 2021 Open Access This article is licensed under a Creative Commons Attribution 4.0 International License, which permits use, sharing, adaptation, distribution and reproduction in any medium or format, as long as you give appropriate credit to the original author(s) and the source, provide a link to the Creative Commons licence, and indicate if changes were made. The images or other third party material in this article are included in the article's Creative Commons licence, unless indicated otherwise in a credit line to the material. If material is not included in the article's Creative Commons licence and your intended use is not permitted by statutory regulation or exceeds the permitted use, you will need to obtain permission directly from the copyright holder. To view a copy of this licence, visit http://creativecommons.org/licenses/by/4.0/ The Creative Commons Public Domain Dedication waiver (http://creativecommons.org/publicdomain/zero/1.0/) applies to the data made available in this article, unless otherwise stated in a credit line to the data. 
behavioral abnormalities, sleep disturbances, and delayed speech development in early childhood. As the disease progresses, deterioration of neurological functions as well as motor skills becomes evident, leading to severe dementia during childhood [3]. In addition, radiologic signs of skeletal dysostosis multiplex are observed [1, 4]. Although musculoskeletal pathologies are less severe in MPS III compared to other MPS types, spine pathologies and a high prevalence of femoral head necrosis have been reported $[4,5]$. The cause of femoral head necrosis in MPS III patients has not yet been histopathologically evaluated. The underlying genetic disease involves accumulation of dermatan and keratin sulfate, which can affect bone development and metabolism by causing inflammation and consequent abnormal bone (re-)modeling; these changes may mimic classical osteonecrotic changes [6-8].

As clinical assessment of hip disease is often challenging due to the hyperactivity and limited communication skills of these patients, hip pathologies might be overlooked. The purpose of this study was to describe hip pathologies and influencing parameters in MPS III patients.

\section{Methods}

A retrospective chart review of 101 MPS III patients treated in the interdisciplinary outpatient clinic was performed (Table 1). The inclusion criteria were a genetically or enzymatically confirmed diagnosis of MPS III and one anteroposterior (AP) radiograph of the hips. Two patients were excluded from the analysis: one had a previous bone marrow transplantation, and the other showed unilateral signs of osteonecrosis of the femoral head, which was graded as classical Perthes' disease. Thirty-two patients met the inclusion criteria.

Due to the clinical variability of MPS III, patients were classified as severe, intermediate, or attenuated based on either the underlying mutation (from known genotypephenotype correlations) or the 4-point scoring system (FPSS) if the mutation was unknown or has not yet been described [3, 9-12]. The FPSS is an instrument assessing the degree of developmental regression (motor function, speech abilities, and cognitive function) over the course of the disease, which enables a classification of the patients into severe, intermediate, and attenuated forms.

Anteroposterior radiographs of the hips were available for all 32 patients. Radiographs were performed in supine position with the hips in neutral rotation. Because of the patients' hyperactivity, frog-leg lateral view radiographs were not routinely performed. For 16 patients, the radiological assessment was performed during a routine consultation as a baseline checkup without clinical signs. For the remaining 16 patients, pain and/or advanced difficulties in walking as well as asymmetry in posture were the indications for radiological evaluation. Radiological images were digitally transferred and

Table 1 Patient characteristics

\begin{tabular}{|c|c|c|c|c|}
\hline \multirow[t]{3}{*}{ Characteristic } & \multirow{3}{*}{$\begin{array}{l}\text { Total } \\
n=32\end{array}$} & \multicolumn{2}{|c|}{ Necrosis of femoral head } & \multirow{3}{*}{$\begin{array}{l}\text { Correlation } \\
\text { to necrosis }\end{array}$} \\
\hline & & No & Yes & \\
\hline & & $n=15(46.9 \%)$ & $n=17(53.1 \%)$ & \\
\hline \multicolumn{5}{|l|}{ Age (years) } \\
\hline Mean \pm SD & $11.0 \pm 5.7$ & $11.1 \pm 6.1$ & $10.9 \pm 5.4$ & \\
\hline Range & & $3.3-27.0$ & $3.4-23.6$ & \\
\hline \multicolumn{5}{|l|}{ Sex-no. (\%) } \\
\hline Male & $21(65.6)$ & $8(38.1)$ & $13(61.9)$ & $p=0.266$ \\
\hline Female & $11(34.4)$ & $7(63.6)$ & $4(36.4)$ & \\
\hline \multicolumn{5}{|c|}{ MPS subtype-no. (\%) } \\
\hline$\| I A$ & $26(81.2)$ & $13(50.0)$ & $13(50.0)$ & $p=0.795$ \\
\hline$\| I \mathrm{~B}$ & $4(12.5)$ & $1(25.0)$ & $3(75.0)$ & \\
\hline$\| I I C$ & $2(6.2)$ & $1(50.0)$ & $1(50.0)$ & \\
\hline \multicolumn{5}{|c|}{ Phenotype-no./total no.(\%) } \\
\hline Severe & $23 / 30(76.7)$ & $9(39.1)$ & $14(60.9)$ & $p=0.036^{*}$ \\
\hline Intermediate & $7 / 30(23.3)$ & $6(85.7)$ & $1(14.3)$ & \\
\hline \multicolumn{5}{|c|}{ Dysplasia-no. (\%) } \\
\hline No & $23(71.9)$ & $13(56.5)$ & $10(43.5)$ & $p=0.04^{*}$ \\
\hline Yes & $9(28.1)$ & $2(22.2)$ & $7(77.8)$ & \\
\hline
\end{tabular}

No. number, SD standard deviation

*Significant 
evaluated by an experienced pediatric orthopedic surgeon using Centricity PACS Universal Viewer (Version 5.0, GE Healthcare, Little Chalfont, UK). An adaption of the modified classification system of Ficat for MPS III patients as published by de Ruijter was used to describe the severity of osteonecrosis of the femoral head (Table 2) [4].

Acetabular coverage was analyzed by measuring Wiberg's center-edge (CE) angle [13], and Reimer's migration percentage (MP) was used as an index of hip migration (Fig. 1) [14]. Dysplasia of the hip was classified using the Severin classification; hips classified as $\geq$ group III were defined as dysplastic [15]. The femoral neckshaft angle was measured only on the AP view of the hip owing to missing lateral views. In addition, classification of the proximal femur regarding valgus and varus deformity was conducted based on the patient's age [16]. It was classified as physiological (angle within reference range) or as varus (angle below reference range) or valgus (angle above reference range) deformity.

Due to the neurocognitive impairment of the patients, clinical signs and symptoms such as pain and changes in walking patterns were reported by parents or caregivers. At the time of the radiological assessment, mobility was classified as unimpaired (no changes in known walking distance, walking time, and posture), impaired (restrictions in known walking distance or walking time but still able to bear weight and walk and/or exhibit postural asymmetry), or lost (reliant on a wheelchair).

All statistical analyses were performed using IBM SPSS Statistics for Windows, version 24.0 (IBM Corp., Armonk, NY, USA) and R statistical software (version 3.5.3). Baseline categorical variables are summarized using frequencies and percentages, and between-group comparisons were performed using Fisher's exact test. Continuous variables are described as the mean \pm standard deviation (SD) values, and Student's $t$-test was applied for between-group comparisons. Paired data from the left and right hips were compared using paired $t$-tests for continuous data and the McNemar-Bowker test for categorical data.

Binary outcomes, e.g., osteonecrosis, pain, and walking ability, were analyzed using univariable logistic regression models applying Firth's correction to the likelihood to account for the small sample size and the limited number of events. Bias-corrected odds ratios (ORs), 95\% confidence intervals (CIs), and $p$-values are reported based on these models. The level of significance for all analyses was set at alpha $=0.05$. Because this was an exploratory study, no adjustment for multiple testing was performed.

\section{Results}

A total of 32 patients (21 males and 11 females) with a mean age of 11.0 years (SD 5.7, range 3.3-27.0 years) were enrolled in the study (Table 1). The mean age of male patients was 11.0 years (SD 5.4, range 3.3-23.6 years), and that of female patients was 11.0 years (SD 6.3, range 4.5-27.0 years). Eighty-one percent of patients presented with subtype MPS IIIA $(n=26)$; four patients had MPS IIIB and two MPS IIIC.

Genetic data were available for all but five patients (84\%). Twenty-three patients (72\%) were categorized as severe, seven $(22 \%)$ as intermediate, and two $(6 \%)$ as unknown; for the unknown category, neither mutation analysis nor the FPSS (due to insufficient clinical data) allowed further classification of the disease severity. No cases of the attenuated disease were identified in the study group.

Osteonecrosis of the femoral head was observed in 17 patients, and 13 out of these 17 patients were bilaterally affected (Table 2, Fig. 2). There was no statistically significant difference between the right and the left hips ( $p$ $=0.306)$. Fifty-nine percent of patients older than 10 years, $60 \%$ of patients from 5 to 10 years of age, and $40 \%$ of patients younger than 5 years of age had osteonecrosis of the head of the femur. Patients with a severe phenotype showed significantly higher rates of osteonecrosis (bias-corrected $\mathrm{OR}=6.6,95 \% \mathrm{CI}[1.1-71], p=0.036$ ), and $82 \%(14 / 17)$ of patients with osteonecrosis exhibited a severe phenotype.

The mean CE angle was $25.3^{\circ}$ (SD 13.4, range - 35.0 to $47.0^{\circ}$ ). A mean of $16 \%$ was found for MP (SD 17.9, range $0-100 \%)$. Dysplasia of at least one hip was documented in $28 \%$ of the patients (9/32, 4 females, 5 males). Four patients were affected unilaterally; 5 were affected bilaterally. All patients with hip dysplasia had a severe phenotype, compared to 14 of 23 patients without dysplasia and a severe phenotype (OR 9.8, 95\% CI [0.99$1331], p=0.052$ ). Focusing on the single hips, a statistically significant association was evident between the presence of hip dysplasia and osteonecrosis of the

Table 2 Adaption of the modified Ficat classification [4] and distribution in study group

\begin{tabular}{ll}
\hline Stage 1 & Minor changes on radiograph \\
Stage $2 \mathrm{~A}$ & Sclerosis or cysts of femoral head, diffuse porosis \\
Stage $2 \mathrm{~B}$ & Crescentic subchondral line, flattening of the femoral head \\
Stage 3 & Broken contour of the head, normal joint space \\
Stage 4 & Collapse, flattened contour of the femoral head, decreased joint space, osteoarthritis \\
\hline
\end{tabular}

Percentage distribution of single hips affected by osteonecrosis $(n=30)$ 


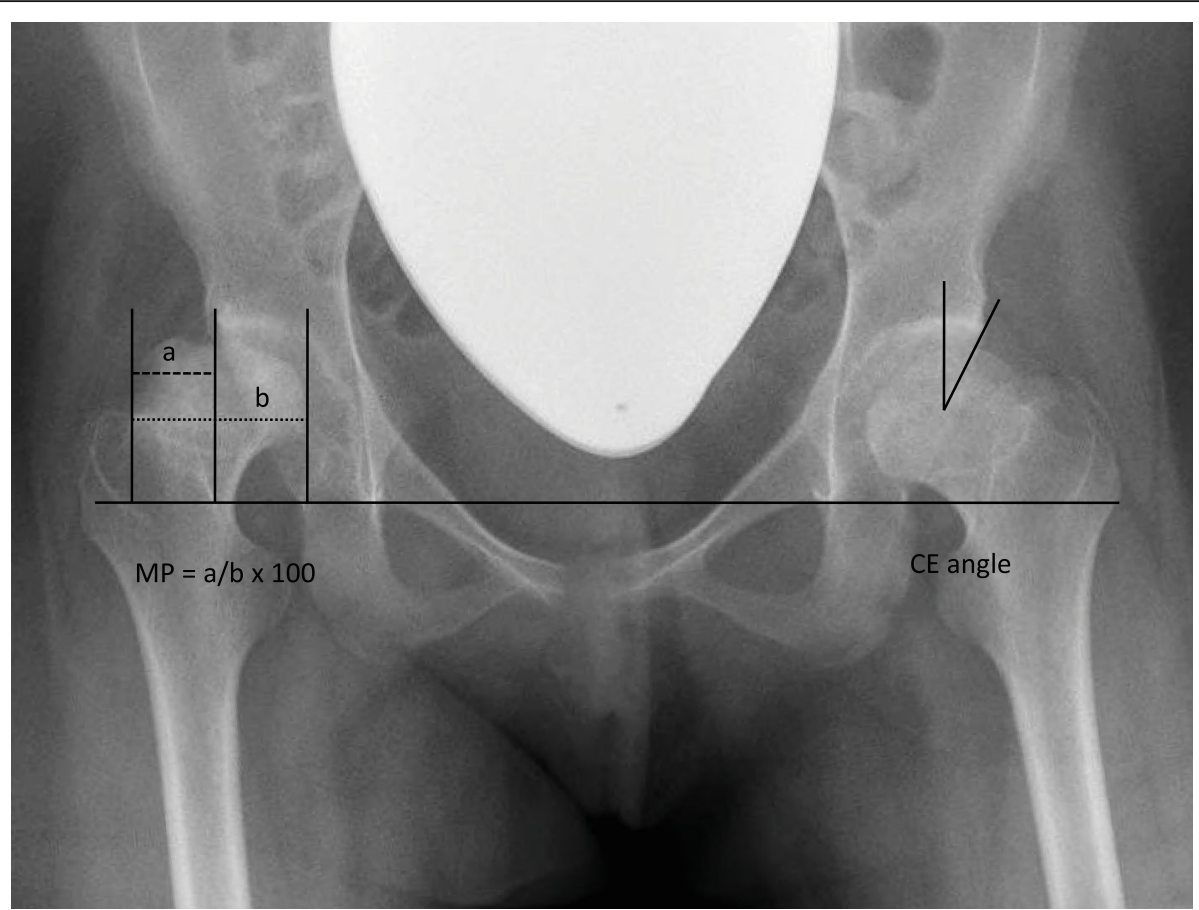

Fig. 1 Radiograph of a 15-year-old severely affected female patient demonstrating measurement of the Reimers percentage (MP, right hip) and Wiberg's center-edge angle (CE, left hip).

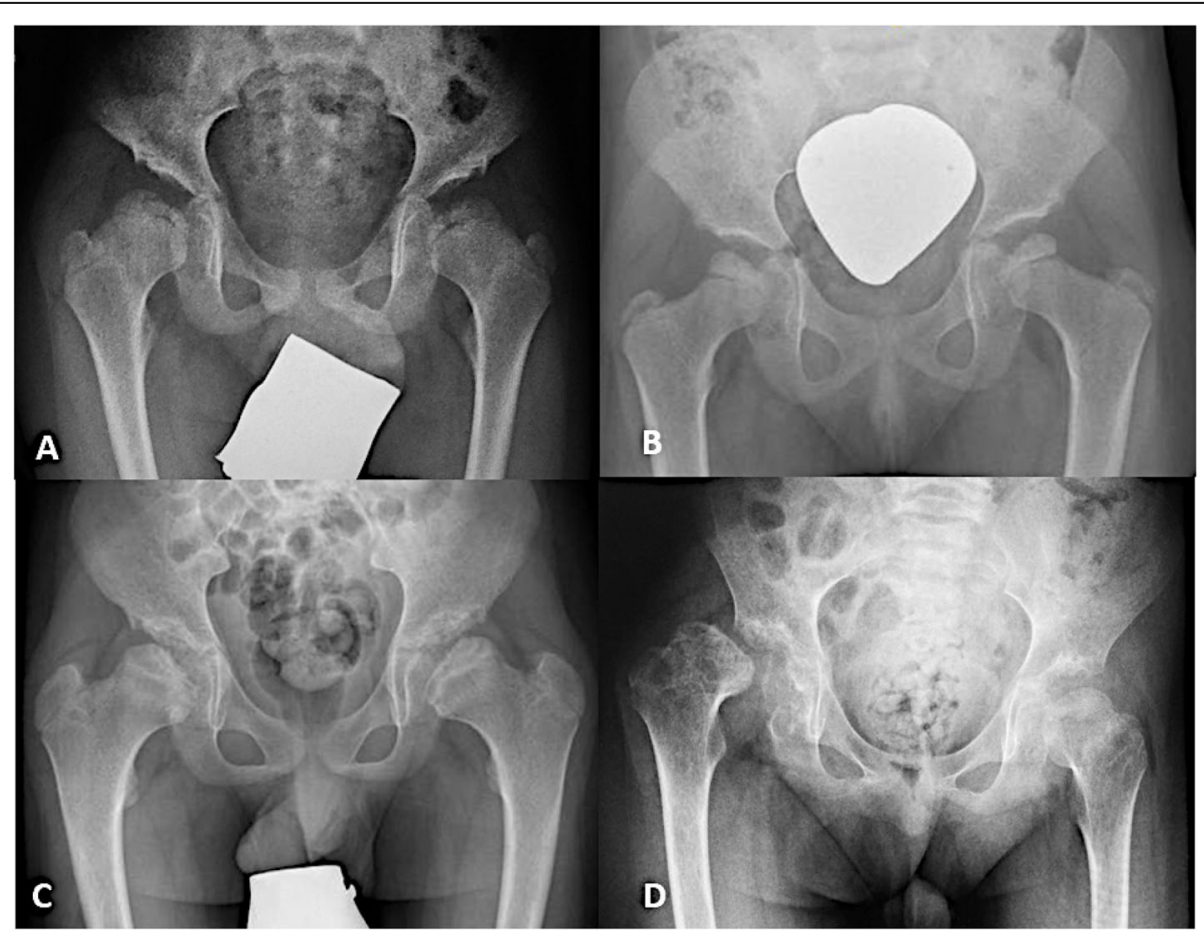

Fig. 2 Presentation of osteonecrosis of the femoral head in severely affected MPS III patients. a An 8-year-old male MPS IIIA patient with severe dysplasia of both hips and osteonecrosis of both femoral heads. b An 8-year-old female MPS IIIA patient with physiological acetabular coverage, but osteonecrosis of the femoral head on both sides. c A 12-year-old male MPS IIIA patient with coxa vara and severely dysplastic acetabular coverage. d A 10-year-old male MPS IIIA patient with osteonecrosis of both femoral heads and dislocation of the right hip joint 
femoral head (bias-corrected OR 3.5, 95\% CI [1.1-13], $p$ $=0.04)$. In contrast, osteonecrosis of the femoral head was documented in $43 \%$ of patients without dysplasia (10/23) (bias-corrected OR 3.9, 95\% CI [0.8-24], $p=$ 0.090). Dysplasia was found in only two patients of 15 without osteonecrosis of the femoral head.

One patient with osteonecrosis of the femoral head also had dislocation of the hip joint (Fig. 2). To alleviate the chronic pain of this patient, a salvage procedure with resection of the femoral head and angulation of the proximal femur was performed.

The anatomy of the femoral neck was described by the femoral neck-shaft angle, with a mean angle of $125.7^{\circ}$ (SD 8.2, range $107-146^{\circ}$ ). In relation to the age of the patient, 53 of 64 hips were in a pathological varus position, and 8 hips were in valgus position; only 3 hips were physiological when compared to reference values (Fig. 3). No statistically significant correlation was observed between the femoral neck-shaft angle and osteonecrosis of the femoral head (OR of one degree increase 1.03, 95\% CI [0.97-1.10], $p=0.312$ ).

Due to the severe cognitive impairment of the patients, personal reports on pain were not collectable. Thus, parents or caregivers reported on the impression of pain in nine cases, and there was no evidence of pain in $21 \mathrm{pa}-$ tients. In two cases, the parents were unsure if their child suffered from pain. Changes in walking pattern or asymmetrical posture were documented for eight patients. Walking abilities were unimpaired in 14 patients and impaired in nine. In addition, nine patients were immobile and reliant on a wheelchair. In this group, seven patients had osteonecrosis of the femoral head of at least one hip, but no statistically significant association between mobility and osteonecrosis of the femoral head was identified (OR of osteonecrosis for impaired walking

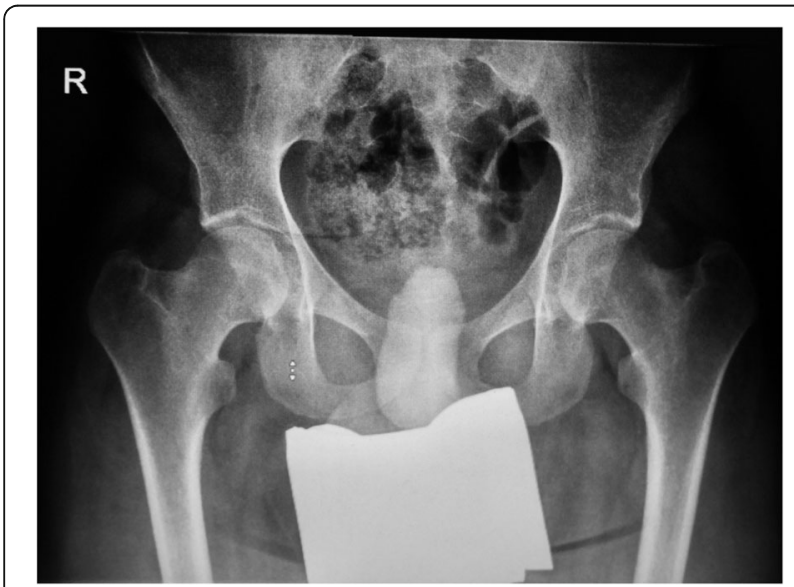

Fig. 3 A 20-year-old MPS IIIA patient with an intermediate phenotype and physiological coverage of the femoral head. The neck of the femur is short and in a varus position. There are no radiographic signs of osteonecrosis of the femoral head abilities 1.2, 95\% CI [0.3-4.9], $p=0.760$, OR for wheelchair reliance $3.9,95 \%$ CI $[0.8-24], p=0.090)$. Moreover, pain was not a predictive indicator for osteonecrosis of the femoral head. Pain was reported in $29 \%(5 / 17)$ of patients with osteonecrosis only, compared to 4 of 15 patients (26\%) without osteonecrosis (OR 1.1, 95\% CI [0.3-5.2], $p=0.877$ ). In the group of patients for whom radiographs were performed as a baseline assessment (patients without clinical symptoms), osteonecrosis was observed in 56\% (9/16).

\section{Discussion}

The present study describes hip pathologies and their influencing parameters in patients with MPS III. The high rate of osteonecrosis of the femoral head in the present study is in accordance with the literature $[4,5]$. The study by de Ruijter et al. assessed 33 patients with MPS III and described signs of osteonecrosis of the femoral head (Ficat stage $\geq 1$ ) in 24\% [4]. The higher rate of $53 \%$ osteonecrosis in the current study can be explained by the lower incidence of intermediate and attenuated disease in the present study population versus the previous study population (intermediate/attenuated cases 22\% versus $52 \%$; severe cases $72 \%$ versus $45 \%$ ). As no femoral head osteonecrosis in patients with an attenuated phenotype was observed, de Ruijter et al. concluded that disease severity appears to be a risk factor for femoral head osteonecrosis in MPS III patients. The present data is supporting this hypothesis. In addition, patients with a severe phenotype showed significantly higher rates of osteonecrosis of the femoral head compared to those with an intermediate phenotype.

Dysplasia of the hip is a common orthopedic pathology in MPS patients. Moreover, it is found in almost all patients with MPS I $\mathrm{H}$ (Hurler syndrome) and can also be present in MPS II, III, IV, and VI [5, 17-20]. In the literature, the rate of hip dysplasia in patients with MPS III varies between 18 and 44\% [4, 5]. In the present study, the rate of hip dysplasia was $28 \%$ and was significantly associated with a high rate of osteonecrosis of the femoral head. Wang et al. described the same significant correlation in MPS IVA patients [20].

Considering that severely affected MPS III patients are at a higher risk of developing osteonecrosis, systemic influence besides mechanical deterioration needs to be discussed. Glycosaminoglycan (GAG) storage, which induces a complex sequence of molecular changes leading to inflammation, synovial hyperplasia, and cartilage apoptosis [8], is assumed to play a major role in joint and bone pathologies in MPS diseases. Animal and human studies investigating the treatment effects of anti-inflammatory drugs such as pentosan polysulfate (PPS) on skeletal pathologies in MPS III are under 


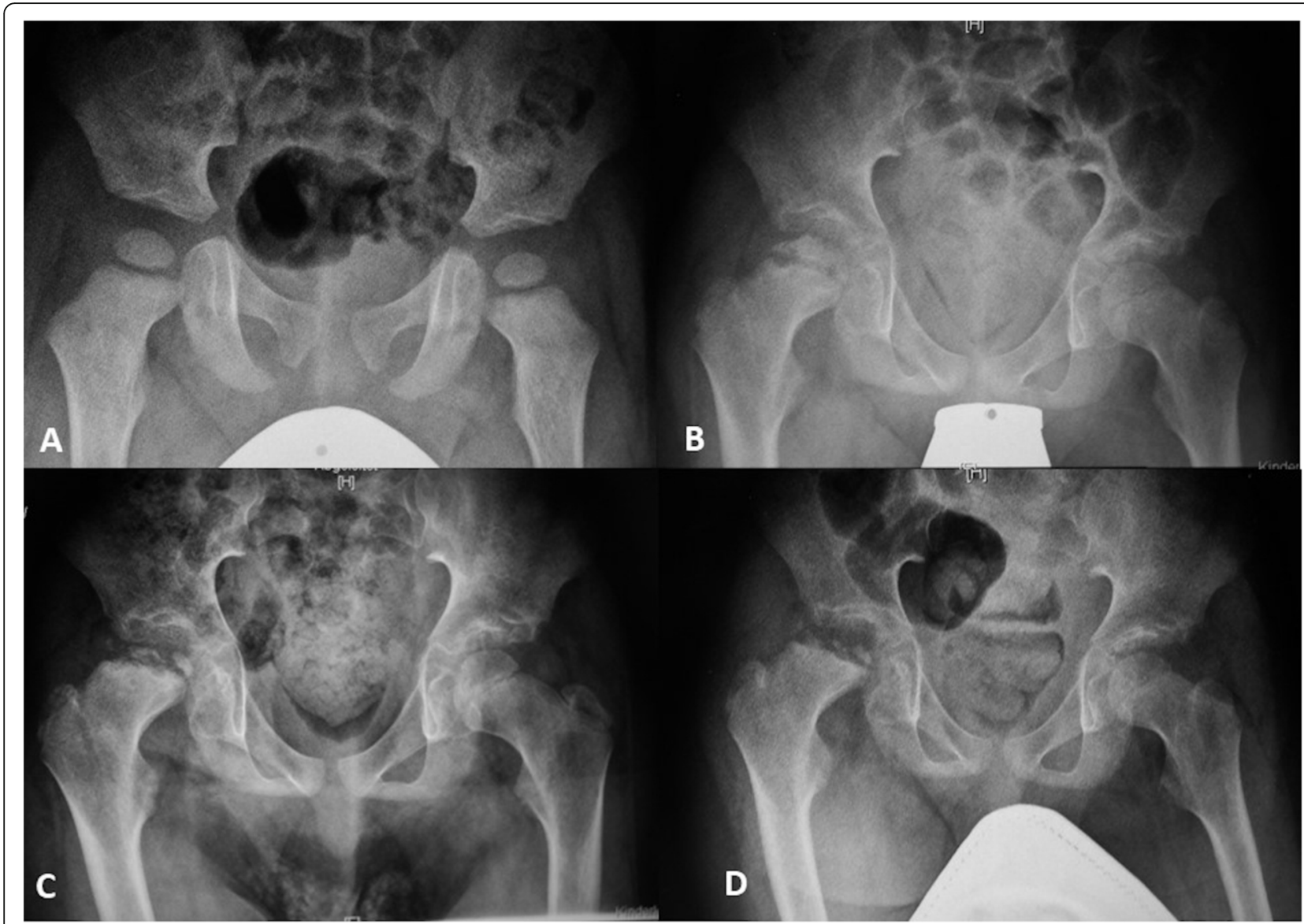

Fig. 4 A male MPS IIIA patient with a severe phenotype. a At 3 years of age, there were no hip pathologies. $\mathbf{b}$ At 10 years of age, Perthes-like necrosis of the right hip was found; note the metaphyseal involvement and the condensation of the epiphysis. $\mathbf{c}$ Seven months later. $\mathbf{d}$ Eleven months after diagnosis

investigation [21]. In addition to inflammation, many studies in various MPS animal models have reported early abnormalities of chondrocyte organization in the growth plate and architecture of cortical bone which could be a trigger for abnormal bone modeling and remodeling leading to secondary hip deformities $[22,23]$. In addition, Nur et al. found a $20 \%$ prevalence of low bone mineral density (BMD) and a $60 \%$ prevalence of vitamin D deficiency in MPS III patients [24]. Although these authors did not report osteonecrosis of the femoral head in the patients, there might be an association, as described earlier for other etiologies, such as alcoholic, steroid-induced, or idiopathic osteonecrosis [25].

The radiological course of osteonecrosis of the femoral head in MPS III patients is in every aspect different than classical Perthes' disease (Fig. 4) [5]. Further studies are necessary to address the question of whether the radiological changes in the femoral heads in MPS III patients comprise osteonecrosis due to avascularity or the substitution and remodeling of healthy bone due to the pathological storage of GAGs.
The limitations of this study are its retrospective design, the different indications for radiographic assessments and the absence of the lateral frog-leg view of the hips. Supine films might not be as reliable as standing radiographs in measuring the severity of dysplasia. Furthermore, due to the neurocognitive impairment of the patients, clinical signs such as pain were based on parents' or caregivers' observations, which might have resulted in underestimation of the true frequency of symptoms.

\section{Conclusions}

The present study demonstrates a high rate of hip pathologies in MPS III patients. Hip dysplasia was seen in $28 \%$ of patients and was significantly correlated with femoral head osteonecrosis. Patients with a severe phenotype were significantly more affected by osteonecrosis of the femoral head (60.9\%). Therefore, radiographs of the hips are highly recommended in routine baseline and follow-up assessments of patients with MPS III. 


\section{Abbreviations}

AP: Anteroposterior; BMD: Bone mineral density; CE: Wiberg's center-edge; Cl: Confidence intervals; FPSS: 4-Point scoring system;

GAG: Glycosaminoglycan; HS: Heparan sulfate; MP: Reimer's migration percentage; MPS: Mucopolysaccharidosis; MPS I H: Hurler syndrome; NAGLU: a-N-acetylglucosaminidase; OR: Odds ratios; PPS: Pentosan polysulfate; SD: Standard deviation; No.: Number

\section{Acknowledgements}

Not applicable.

\section{Authors' contributions}

$S R B$ measured the radiographs and made substantial contributions to the study conception, data analysis, and interpretation; she was involved in drafting the manuscript. EV was involved in drafting the statistical analyses and interpretation of the data. LS was involved in drafting the statistical analyses. AG was involved in language editing and revised the manuscript critically. KMvC made substantial contributions to data acquisition. AS was involved in revising the manuscript. MR was involved in revising the manuscript. RS was involved in the study conception, interpretation of the data, and revising the manuscript. NMM made substantial contributions to the study conception and design and to data analysis and interpretation; she was involved in drafting the manuscript and revising it critically for important intellectual content. All authors read and approved the final manuscript.

\section{Funding}

Open Access funding enabled and organized by Projekt DEAL.

\section{Availability of data and materials}

The datasets used and analyzed during the current study are available from the corresponding author on reasonable request.

\section{Declarations}

Ethics approval and consent to participate

Ethics approval is not necessary for retrospective studies in accordance with state law ( $\$ 12 \mathrm{HmbKHG}$ ) at our institution.

\section{Consent for publication}

Consent for publication was obtained.

\section{Competing interests}

The authors declare no competing interests.

\section{Author details}

'Department of Pediatric Orthopedics, Children's Hospital Altona, Bleickenallee 38, 22763 Hamburg, Germany. ${ }^{2}$ Department of Orthopedics, University Medical Center Hamburg-Eppendorf, 20246 Hamburg, Germany. ${ }^{3}$ International Center for Lysosomal Disorders, University Medical Center Hamburg-Eppendorf, 20246 Hamburg, Germany. ${ }^{4}$ Department of Medical Biometry and Epidemiology, University Medical Center Hamburg-Eppendorf, 20246 Hamburg, Germany. ${ }^{5}$ Department of Pediatrics, University Medical Center Hamburg-Eppendorf, 20246 Hamburg, Germany.

Received: 5 November 2020 Accepted: 9 March 2021

Published online: 19 March 2021

\section{References}

1. Cleary MA, Wraith JE. Management of mucopolysaccharidosis type III. Arch Dis Child. 1993;69(3):403-6. https://doi.org/10.1136/adc.69.3.403.

2. Baehner F, Schmiedeskamp C, Krummenauer F, Miebach E, Bajbouj M, Whybra C, Kohlschütter A, Kampmann C, Beck M. Cumulative incidence rates of the mucopolysaccharidoses in Germany. J Inherit Metab Dis. 2005; 28(6):1011-7. https://doi.org/10.1007/s10545-005-0112-z.

3. Meyer A, Kossow K, Gal A, Muhlhausen C, Ullrich K, Braulke T, Muschol N. Scoring evaluation of the natural course of mucopolysaccharidosis type IIIA (Sanfilippo syndrome type A). Pediatrics. 2007;120(5):e1255-61. https://doi. org/10.1542/peds.2007-0282.

4. de Ruijter J, Maas M, Janssen A, Wijburg FA. High prevalence of femora head necrosis in mucopolysaccharidosis type III (Sanfilippo disease): a national, observational, cross-sectional study. Mol Genet Metab. 2013;109(1): 49-53. https://doi.org/10.1016/j.ymgme.2013.03.004.

5. White KK, Karol LA, White DR, Hale S. Musculoskeletal manifestations of Sanfilippo syndrome (mucopolysaccharidosis type III). J Pediatr Orthop. 2011;31(5):594-8. https://doi.org/10.1097/BPO.0b013e31821f5ee9.

6. Oussoren E, Brands MM, Ruijter GJ, der Ploeg AT, Reuser AJ. Bone, joint and tooth development in mucopolysaccharidoses: relevance to therapeutic options. Biochim Biophys Acta. 2011;1812(11):1542-56. https://doi.org/10.1 016/j.bbadis.2011.07.013

7. White KK, Harmatz P. Orthopedic management of mucopolysaccharide disease. J Pediatr Rehabil Med. 2010;3(1):47-56. https://doi.org/10.3233/ PRM-2010-0102.

8. Simonaro CM, D'Angelo M, He X, Eliyahu E, Shtraizent N, Haskins ME, et al. Mechanism of glycosaminoglycan-mediated bone and joint disease: implications for the mucopolysaccharidoses and other connective tissue diseases. Am J Pathol. 2008;172(1):112-22. https://doi.org/10.2353/ajpath.2 008.070564

9. Yogalingam G, Hopwood JJ. Molecular genetics of mucopolysaccharidosis type IIIA and IIIB: diagnostic, clinical, and biological implications. Hum Mutat. 2001;18(4):264-81. https://doi.org/10.1002/humu.1189.

10. Perkins KJ, Byers S, Yogalingam G, Weber B, Hopwood JJ. Expression and characterization of wild type and mutant recombinant human sulfamidase. Implications for Sanfilippo (Mucopolysaccharidosis IIIA) syndrome. J Biol Chem. 1999;274(52):37193-9. https://doi.org/10.1074/ jbc.274.52.37193.

11. Meyer A, Kossow K, Gal A, Steglich C, Muhlhausen C, Ullrich K, et al. The mutation p.Ser298Pro in the sulphamidase gene (SGSH) is associated with a slowly progressive clinical phenotype in mucopolysaccharidosis type IIIA (Sanfilippo A syndrome). Hum Mutat. 2008;29(5):770

12. Bunge $\mathrm{S}$, Ince $H$, Steglich $C$, Kleijer WJ, Beck M, Zaremba J, van Diggelen OP, Weber B, Hopwood JJ, Gal A. Identification of 16 sulfamidase gene mutations including the common R74C in patients with mucopolysaccharidosis type IIIA (Sanfilippo A). Hum Mutat. 1997;10(6):47985. https://doi.org/10.1002/(SICI)1098-1004(1997)10:6<479::AID-HUMU10>3.0. $\mathrm{CO} ; 2-\mathrm{X}$

13. Wiberg G. Studies on dysplastic acetabula and congenital subluxation of the hip joint: with special reference to the complication of osteoarthritis. Acta Chir Scand. 1939:83:53-68.

14. Reimers J. The stability of the hip in children. A radiological study of the results of muscle surgery in cerebral palsy. Acta Orthop Scand Suppl. 1980; 184:1-100. https://doi.org/10.3109/ort.1980.51.suppl-184.01.

15. Ali AM, Angliss R, Fujii G, Smith DM, Benson MK. Reliability of the Severin classification in the assessment of developmental dysplasia of the hip. J Pediatr Orthop B. 2001;10(4):293-7.

16. Hefti F. Kinderorthopädie in der Praxis. 1st ed. Berlin: Springer; 1997. p. 173.

17. Breyer SR, Muschol N, Schmidt M, Rupprecht M, Babin K, Herrmann J, Stücker R. Hip morphology in MPS-1H patients: an MRI-based study. J Pediatr Orthop. 2018;38(9):478-83. https://doi.org/10.1097/BPO. 0000000000000858

18. Oussoren E, Bessems J, Pollet V, van der Meijden JC, van der Giessen $L$, Plug I, et al. A long term follow-up study of the development of hip disease in mucopolysaccharidosis type VI. Mol Genet Metab. 2017;121(3):241-51. https://doi.org/10.1016/j.ymgme.2017.05.008.

19. Williams N, Challoumas D, Ketteridge D, Cundy PJ, Eastwood DM. The mucopolysaccharidoses: advances in medical care lead to challenges in orthopaedic surgical care. Bone Joint J. 2017;99-B(9):1132-9. https://doi. org/10.1302/0301-620X.99B9.BJJ-2017-0487.

20. Wang Z, Xu Y, Jiang E, Wang J, Tomatsu S, Shen K. Pathophysiology of hip disorders in patients with mucopolysaccharidosis IVA. Diagnostics (Basel). 2020;10(5):264

21. Guo N, DeAngelis V, Zhu C, Schuchman EH, Simonaro CM. Pentosan polysulfate treatment of mucopolysaccharidosis type IIIA mice. JIMD Rep. 2019;43:37-52. https://doi.org/10.1007/8904_2018_96.

22. Heppner JM, Zaucke F, Clarke LA. Extracellular matrix disruption is an early event in the pathogenesis of skeletal disease in mucopolysaccharidosis I. Mol Genet Metab. 2015;114(2):146-55. https:// doi.org/10.1016/j.ymgme.2014.09.012.

23. Clarke LA. Pathogenesis of skeletal and connective tissue involvement in the mucopolysaccharidoses: glycosaminoglycan storage is merely the instigator. Rheumatology (Oxford). 2011;50(Suppl 5):v13-8. https://doi.org/1 0.1093/rheumatology/ker395. 
24. Nur BG, Nur H, Mihci E. Bone mineral density in patients with mucopolysaccharidosis type III. J Bone Miner Metab. 2017;35(3):338-43. https://doi.org/10.1007/s00774-016-0762-y.

25. Tian L, Baek SH, Jang J, Kim SY. Imbalanced bone turnover markers and low bone mineral density in patients with osteonecrosis of the femoral head. Int Orthop. 2018;42(7):1545-9. https://doi.org/10.1007/s00264-018-3902-2.

\section{Publisher's Note}

Springer Nature remains neutral with regard to jurisdictional claims in published maps and institutional affiliations.

Ready to submit your research? Choose BMC and benefit from:

- fast, convenient online submission

- thorough peer review by experienced researchers in your field

- rapid publication on acceptance

- support for research data, including large and complex data types

- gold Open Access which fosters wider collaboration and increased citations

- maximum visibility for your research: over $100 \mathrm{M}$ website views per year

At BMC, research is always in progress. 